\title{
Metabolic Effects of Endogenous and Exogenous Heterotropic Hemoglobin Modulators on Anion Transport: The Case of Pig Erythrocytes
}

\author{
Ester Tellone $^{1 *}$, Annamaria Russo ${ }^{1}$, Bruno Giardina ${ }^{2,3}$, Antonio Galtieri ${ }^{1}$, Silvana Ficarra ${ }^{1}$ \\ ${ }^{1}$ Department of Chemical Sciences, University of Messina, Messina, Italy \\ ${ }^{2}$ Biochemistry and Clinical Biochemistry Institute, Catholic University, School of Medicine, Rome, Italy \\ ${ }^{3}$ C.N.R. Institute of Chemistry of Molecular Recognition, Rome, Italy \\ Email: ${ }^{*}$ etellone@unime.it
}

Received 29 September 2015; accepted 15 October 2015; published 21 October 2015

Copyright (C) 2015 by authors and OALib.

This work is licensed under the Creative Commons Attribution International License (CC BY).

http://creativecommons.org/licenses/by/4.0/

$$
\text { (c) (i) Open Access }
$$

\section{Abstract}

This comparative study, focused on the anion kinetic of band 3 protein of pig erythrocytes, investigates in vitro the metabolic functionality of the red blood cells of this mammal which show particular characteristics of the cell membrane and significant stoichiometric variations of several cytosolic components. Pig red blood cells compared to human ones, are characterized by a higher anion flux strongly modulated by the conformational transition state (T-R) of hemoglobin; these findings are probably connected to the intracellular concentration of 2,3-disphosphoglycerate and to chloride activity. The experimental use, alone or in combination, of some exogenous heterotropic modulators of hemoglobin as orthovanadate, gemfibrozil and resveratrol, shows characteristic modulations of the anion flux which are related to the cytosolic metabolites physiologically present in pig erythrocytes, to the metabolism and oxidative stress. Our findings highlight new features about the pig red blood cells functionality and contribute to extending the current understanding of their life cycle, providing opportunities for new investigations in the field of comparative physiology.

\section{Keywords}

Band 3 Protein, 2,3-Diphosphoglycerate, Hemoglobin, Metabolism, Red Blood Cell

Subject Areas: Biochemistry

\footnotetext{
${ }^{*}$ Corresponding author.

How to cite this paper: Tellone, E., Russo, A., Giardina, B., Galtieri, A. and Ficarra, S. (2015) Metabolic Effects of Endogenous and Exogenous Heterotropic Hemoglobin Modulators on Anion Transport: The Case of Pig Erythrocytes. Open Access Library Journal, 2: e1994. http://dx.doi.org/10.4236/oalib.1101994
} 


\section{Introduction}

Erythrocytes play a key role in human and vertebrate metabolism. Despite being similar in basic structure and serving equally important physiological functions in all mammals, red blood cells (RBCs) differ vastly in their rheological properties in different species. Comparative studies are designed to give relevant information on the structural and functional basis of RBCs rheological behavior itself. Information gathered in comparative studies can thus serve as a basis for experimental models investigating physiological phenomena in different animal species.

Pig RBCs share several common characteristics with human erythrocytes. Pig RBC diameters and counts are similar, although the average life span of pig erythrocytes is shorter than that of human ones. The knowledge acquired to date on porcine blood shows that it is characterized by a high intraerythrocyte concentration of 2,3diphosphoglycerate (2,3-DPG) (8 - $10 \mathrm{mM})$ [1] [2] and the hemoglobin (Hb) shows a low temperature sensitivity. In addition, pig RBCs have the slowest metabolic rate of any mammalian cell type [3]; they contain both hexokinase (EC 2.7.1.1) types II and III, the latter being the predominant form accounting almost for $98 \%$ of the total glucose phosphorylating activity [4]. The adult pig erythrocyte is able to utilize $0.27 \mu \mathrm{mol}$ of glucose $\mathrm{h} / \mathrm{ml}$ RBC vs $0.56-2.85 \mu \mathrm{mol} / \mathrm{h} / \mathrm{ml} \mathrm{RBC}$ for the other mammalian species. This reduced capacity to metabolize glucose results from a relatively poor ability of the cell membrane to transport glucose. In fact, in spite of the presence of all the glycolytic enzymes (GE), a low intracellular glucose concentration has been measured $(0.5 \mathrm{mM}$ against a plasma level of $5 \mathrm{mM}$ ) [5]. Evidences have been presented showing that pig RBCs supply their energy metabolic substrate with inosine [6]. However, the inosine at physiological concentrations does not seem to be as efficient as glucose in maintaining reduced glutathione levels under oxidative stress, whereas in the pig blood and RBCs catalase activity was found to be high [5] [7] [8].

All these observations led us to study pig RBCs by comparing them with the human erythrocytes. Particular attention was directed to the function of band 3 (AE1 or B3), an integral protein widely expressed in the RBC membrane $\left(1.2 \times 10^{6}\right.$ copies for RBC).

B3 mediates the electroneutral exchange of anions across the plasma membrane effectively contributing to the elimination of $\mathrm{CO}_{2}$. The protein exposes both the $\mathrm{N}$-terminus and the C-terminal on the cytosolic face of the membrane, stabilizing the structure of the cytoskeleton and contributing to regulating the erythrocyte metabolism. In fact, the short C-terminal cytoplasmic domain binds carbonic anhydrase II and the N-terminal cytoplasmic domain interacts with a variety of proteins, including $\mathrm{Hb}$ and some GE; moreover it anchors the RBC membrane to the cytoskeleton through ankyrin and protein 4.2 [9]. The competitive binding of deoxy-Hb and GE with respect of B3 drives the sophisticated oxygen-dependent regulation of erythrocyte metabolism directing the glucose 6 phosphate (G6P), in a time-dependent manner, to the pentose phosphate pathway (PPP) in the oxygenated erythrocytes (HOS, high-oxygenation state, about 90\% saturation), and to the Embden-Meyerhof pathway (EMP) in the low oxygenation state of the RBC (LOS, low-oxygenation state, about 15\% saturation) [10]-[12]. The correct modulation of the G6P metabolism (centered on the deoxygenation-oxygenation cycle of $\mathrm{Hb}$ ) protects erythrocytes against oxidative stress and maintains their structural and functional integrity, guaranteeing an adequate life cycle. Studies of membrane B3 functionality in pig RBCs and its correlation with erythrocyte metabolic events can be of interest in veterinary medicine and provide new general knowledge about the functionality of the RBCs.

\section{Materials and Methods}

\subsection{Materials}

All reagents were from Sigma-Aldrich (St. Louis, MO, USA). Fresh blood samples from pig (Sus scrofa domesticus), collected into iso-osmotic $0.15 \mathrm{M} \mathrm{NaCl}, \mathrm{pH} 7.4$, containing $2 \mathrm{mM}$ EDTA, were obtained from a slaughterhouse. Citrate fresh human blood was obtained from informed healthy donors under the declaration that they had avoided any drug treatment at least one week before sample collection, in accordance with the principles outlined in the Declaration of Helsinki and immediately processed.

\subsection{Preparation of Erythrocytes}

Citrate blood samples were washed three times with an iso-osmotic $\mathrm{NaCl}$ solution. During washing, white blood cells were discarded from the pellet. After washing, the RBCs were resuspended (haematocrit 3\%) in the incuba- 
tion buffer (35 mM Na $\mathrm{SO}_{4}, 90 \mathrm{mM} \mathrm{NaCl}, 25 \mathrm{mM}$ HEPES [ $N$-(2-hydroxyethyl)-piperazine- $N^{1}$-2-ethanesul-fonic acid], $1.5 \mathrm{mM} \mathrm{MgCl}$ ), adjusted to $\mathrm{pH} 7.4$ or 7.3 and $310 \pm 20 \mathrm{mOsmol}$ per kg, measured by an Osmostat OM-6020 apparatus (Daiichikagakuco, Kyoto, Japan). In experiments performed with deoxygenated erythrocytes, samples were submitted to cycles of vacuum deoxygenation and nitrogen (ultrapure) saturation at a pressure of $100 \mathrm{kPa}$. This treatment allowed us to obtain different levels of deoxygenation (from $15 \%$ up to 90\%), which were checked by determining $\mathrm{Hb}$ saturation spectrophotometrically (Beckman DU 640 spectrophotometer) using the millimolar absorptivities reported by Zijlstra et al. [13]. The buffer used to prepare deoxygenated erythrocytes was $0.1 \mathrm{pH}$ unit lower than that used for oxygenated erythrocytes, in order to compensate for the Haldane effect that occurs during deoxygenation [14]. Thus, after deoxygenation, the external pHs of oxygenated and deoxygenated samples differed by no more than $0.03 \mathrm{pH}$ unit.

Met-hemoglobin (met-Hb) levels and the degree of haemolysis were determined at the end of the incubation time as follows: haemolysis was measured spectrophotometrically; Hb concentration in the supernatants was obtained from a centrifugation at $2500 \times g$ for $5 \mathrm{~min}$ at $4^{\circ} \mathrm{C}$; met-Hb levels were determined spectrophotometrically on lysed cells [13].

\subsection{Preparation of RBC Ghosts}

Washed erythrocytes were lysed with iced hypotonic medium containing $5 \mathrm{mM}$ Tris and $5 \mathrm{mM} \mathrm{KCl}$. After haemolysis the $\mathrm{Hb}$ and the intracellular contents were eliminated by centrifugation. The membranes were resealed by incubation at $37^{\circ} \mathrm{C}$ for one hour with a closing buffer. The resealed ghosts were suspended in the same buffer used for sulphate transport in entire RBCs.

\subsection{Measurement of ODCs}

Stripped $\mathrm{Hb}$ was obtained by passing the haemolysate through a Sephadex G-25 column equilibrated with $0.1 \mathrm{M}$ HEPES buffer, $\mathrm{pH}$ 7.4, containing $0.1 \mathrm{M} \mathrm{NaCl}$. Concentrated stock solutions of 2,3-DPG and resveratrol (RV) were prepared by dissolving the first in HEPES buffer and the last in ethanol. A number of $\mathrm{O}_{2}$ equilibrium experiments were performed on purified $\mathrm{Hb}$ in order to obtain quantitative data on oxygen affinity. The oxygen binding properties of human and pig Hb solutions were investigated at $\mathrm{pH} 7.4$ both in the absence and in presence of $0.1 \mathrm{mM} \mathrm{RV} . \mathrm{P}_{50}$ (partial pressure of the ligand at which $50 \%$ of haemes is oxygenated) and $n$ (hill coefficient; an empirical index of cooperativity) values, were determined at $37^{\circ} \mathrm{C}$ from absorbance changes accompanying the dioxygen molecule binding by the tonometric method, in the presence of the physiological allosteric effector 2,3-DPG (3 mM), as well as in the presence of RV [15]. An average standard deviation of $\pm 8 \%$ for values of $\mathrm{P}_{50}$ was calculated. Met-Hb content never exceeding $2 \%$ in any of the experimental conditions.

\subsection{Kinetic Measurements}

Cells were incubated in the above incubation buffer at $25^{\circ} \mathrm{C}$, under different experimental conditions. Concentrated stock solutions of RV, orthovanadate (OV) and gemfibrozil (GFZ) were prepared by dissolving them respectively in ethanol, HEPES buffer and dimethyl sulphoxide (DMSO). At several time intervals, 10 micromoles of the stopping medium SITS (4-acetamido-4'-isothiocyanostilbene-2,2'-disulfonic acid) was added to each test tube containing the RBCs suspension at periodic time intervals (from 5 to 120 minutes). Cells were separated from the incubation medium by centrifugation (J2-HS Centrifuge, Beckman, Palo Alto, CA, USA) and washed three times at $4^{\circ} \mathrm{C}$ with a sulphate-free medium to remove the sulphate trapped on the outside. After the final washing, the packed cells were lysed with perchloric acid (4\%) and distilled water. Lysates were centrifuged for $10 \mathrm{~min}$ at $4000 \times \mathrm{g}\left(4^{\circ} \mathrm{C}\right)$ and membranes were separated from the supernatant. Sulphate ions were precipitated from the supernatant by adding a glycerol/distilled water mixture $(1: 1, \mathrm{~V} / \mathrm{V}), 4 \mathrm{M} \mathrm{NaCl}$ and $1 \mathrm{M}$ $\mathrm{HCl}, 1.23 \mathrm{M} \mathrm{BaCl}_{2} \cdot 2 \mathrm{H}_{2} \mathrm{O}$ to obtain a homogeneous barium sulphate precipitate. The absorbance of this suspension was measured at $350-425 \mathrm{~nm}$. Sulphate concentration was determined using a calibrated standard curve, obtained by measuring the absorbance of suspensions with known amounts of sulphate [16]. The sulphate kinetic analysis of human and pig RBC solutions were investigated both in the absence and in presence of $0.1 \mathrm{mM}$ $\mathrm{RV}, 3 \mathrm{mM} \mathrm{OV}$ and $3 \mathrm{mM}$ GFZ.

The experimental data on sulphate concentration as a function of the incubation time were analyzed by best fit procedures using the following equation: $c(t)=c_{\infty}\left(1-\mathrm{e}^{-k t}\right)$ where $c(t)$ represents sulphate concentration at time $t$, 
$c_{\infty}$ intracellular sulphate concentration at equilibrium, and $k$ the rate constant of sulphate influx.

\subsection{Statistical Analysis}

Data are presented as mean \pm standard deviation (S.D.). The data were analysed by one-way analysis of variance (ANOVA). The significance of the differences in relation to the respective controls for each experimental test condition were calculated using the Student's $t$-test for each paired experiment. A $P<0.05$ was regarded as indicating a significant difference.

\section{Results}

Our previous work highlighted that in adult human erythrocytes sulphate transport across the membrane is modulated by the pressure of oxygen and therefore by the oxygen-linked transition of $\mathrm{Hb}$ [17]. The same study performed on pig erythrocytes is shown in Figure 1 and Figure 2. The dependence of the anion influx rate on log $\mathrm{pO}_{2}$ both in human and in pig RBCs is clearly evident. It is possible to note that, in both cases, the B3 activity is higher for HOS with respect to LOS and that the modulation of the flux induced by oxygen through the oxygen-dependent conformational change of $\mathrm{Hb}$ remains even in the pig RBCs.

These findings lead us to assume that the interaction between $\mathrm{Hb}$ and B3 is not profoundly altered by the amminoacid substitutions found in the B3 sequence of pig in comparison to that of human B3 [18]. The higher level of anion transport found in pig RBCs with respect to human cells, may depend on several factors, one of

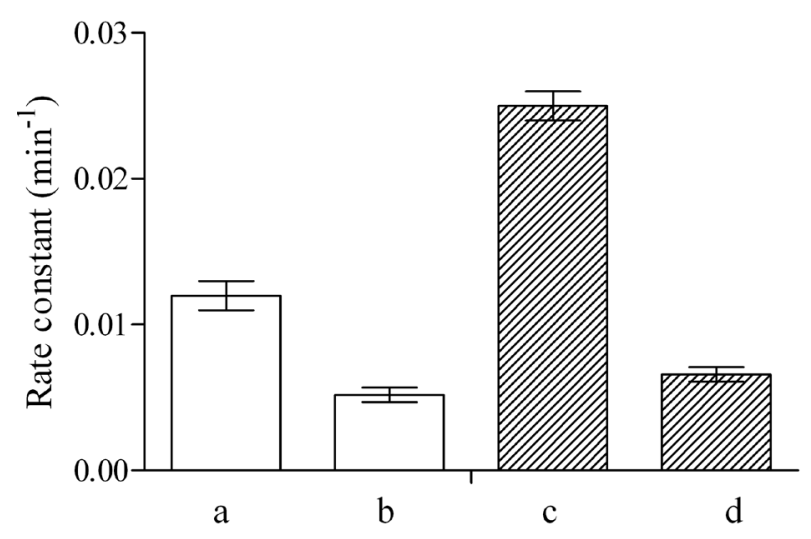

Figure 1. Rates of sulphate transport in human (white boxes) and pig (shaded boxes) RBCs at high (a, c) and low (b, d) oxygen saturation $(P<0.05$ was considered significant).

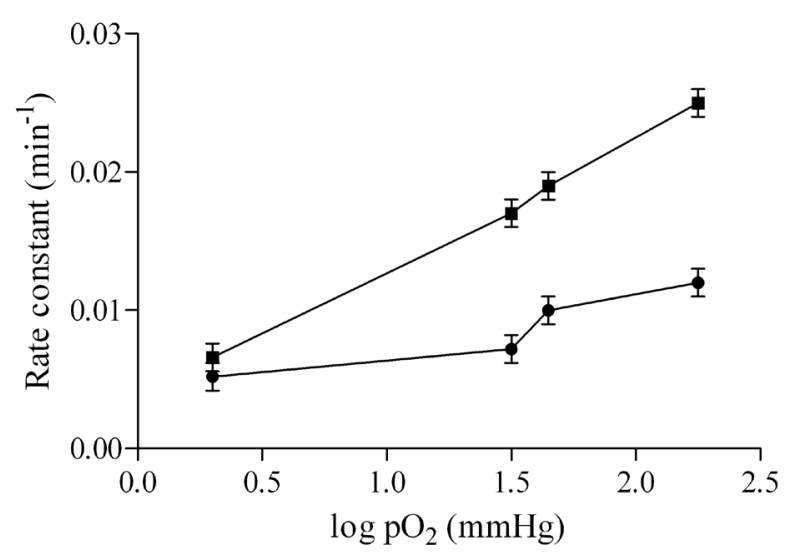

Figure 2. Rates of sulphate influx determined in human $(\bullet)$ and pig (ם) erythrocytes under different oxygen pressure. For experimental conditions see Materials and Methods. 
which could be the high intraerythrocytic concentration of 2,3-DPG. Hence, 2,3-DPG interacting directly with B3 [19] may cause structural changes responsible for the increase of anion flux. In this regard some of our experiments on the anion kinetics in human RBCs incubated with 2,3-DPG (3 mM) that have shown an increased functionality of the B3 could be mentioned. In particular, the rate constant (RC) switches from a value of 0.012 $\min ^{-1}$ to $0.025 \mathrm{~min}^{-1}$, assuming an exchanging rate very similar to that recorded for the pig RBCs.

Figure 3 shows some experiments on anion kinetics carried out on ghosts. These structures lack of several cytoplasmic factors that modulate the anion transport, among which $\mathrm{Hb}$ is the most representative. Then kinetic measurements of anion exchange in ghosts are a clear indicator of the importance of these metabolites on the modulation of the B3 and the relationship between the RC of RBCs and ghosts is an index that allows to evaluate the interference of cytosolic factors on the anion kinetics. This interference is directly proportional to the value of the ratio $\left(\mathrm{RC}_{\text {ghosts }}\right) /\left(\mathrm{RC}_{\mathrm{RBCS}}\right)$ and more this value differs from 1 by increasing, the greater will be the cytosolic modulation on the anion kinetics.

Looking closely at the two graphs (Figure 1 and Figure 3 ) is possible to note that the value of this ratio is $1.72\left(0.043 \mathrm{~min}^{-1} / 0.025 \mathrm{~min}^{-1}\right)$ for pig and $2.83\left(0.034 \mathrm{~min}^{-1} / 0.012 \mathrm{~min}^{-1}\right)$ for human indicating that in pig the interference of cytosolic metabolites is reduced by about $40 \%$ in HOS conditions while in LOS the cytosolic modulation on B3 is similar in the two species.

What observed could be once again related to the pig intraerythrocyte concentration of 2,3-DPG and particularly to the action of the latter on the phosphorylation state of the B3 [20] [21]. To test this hypothesis we performed a set of experiments in the presence of OV, a phosphatase inhibitor [22] well known to affect protein phosphorylation, including band 3 cytoplasmic domain (cdb3) [23] [24]. In terms of anion flux (Figure 4), the results show that OV induce a significant increase of the B3 activity both in human and pig RBCs; the analysis of the percentage of increase of the anion exchange in the presence of OV (about 30\% in human and 20\% in pig RBCs) indicates a difference between the two types of cells. To evaluate the metabolic responses of pig erythrocytes compared to human ones and in the light of the acquired experiences we also tested two different drugs: GFZ and RV which are known to bind Hb [25]-[27]. GFZ belongs to the group of fibric acid derivatives, utilized as antihyperlipidemia agents with the main aim to reduce incidence of coronary heart disease [28] [29]; RV, an important phytoalexine found in many plants, has been shown to be significantly effective in the treatment of several pathological conditions such as cancer, coronary heart disease and osteoarthritis [30]-[32]. The results shown in Figure 4 highlight a different response of the pig RBCs to the two drugs that becomes more evident when compared to human RBCs. In the presence of GFZ, pig RBCs increase their kinetic of anion flux and this increase have the same intensity of human ones. Different is the response in the presence of RV, because even if both pig and human RBCs increase their anion exchange, the percentage of increase is lower in the pig RBCs than in human ones.

The same kinetic experiments were performed on ghosts, and from the results shown in Figure 5, it is possible to note that even in these conditions there is an increase of anion exchange both for human and pig RBCs. The small increment of B3 activity in ghosts compared to the intact RBCs can be due to the absence of several

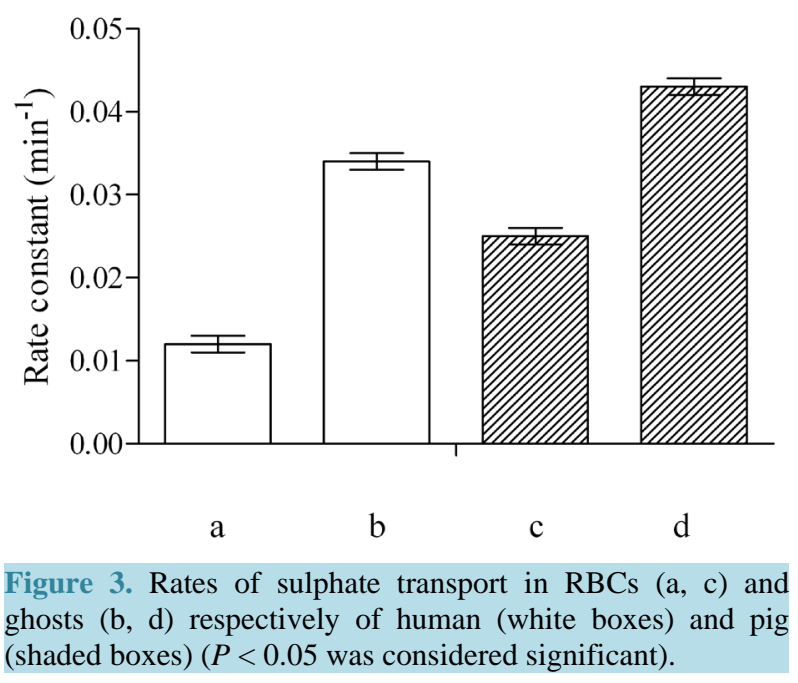




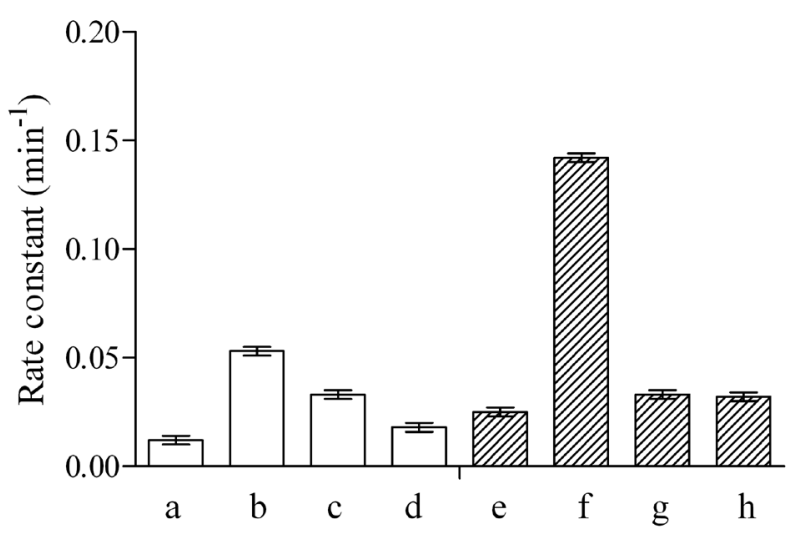

Figure 4. Rates of sulphate transport in human (white boxes) and pig (shaded boxes) RBCs in absence (a, e) and presence of $3 \mathrm{mM} \mathrm{GFZ} \mathrm{(b,} \mathrm{f),} 0.1 \mathrm{mM} \mathrm{RV} \mathrm{(c,} \mathrm{g)} \mathrm{and} 3 \mathrm{mM} \mathrm{OV} \mathrm{(d,} \mathrm{h)}$ $(P<0.05$ was considered significant).

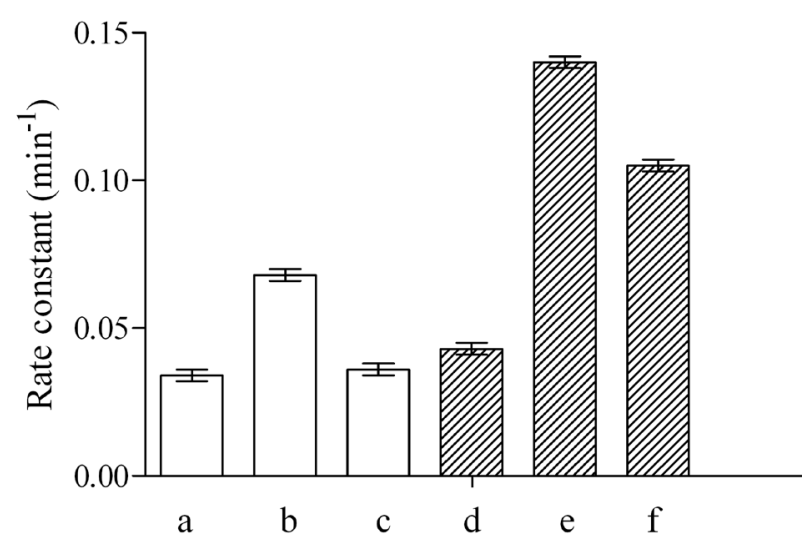

Figure 5. Rates of sulphate transport in human (white boxes) and pig (shaded boxes) ghosts in absence (a, d) and presence of 3 mM GFZ (b, e) and $0.1 \mathrm{mM} \mathrm{RV} \mathrm{(c,} \mathrm{f)}(P<0.05$ was considered significant).

cytoplasmic factors that modulate the anion transport among which Hb and 2,3-DPG are the most representative.

In order to go deeper into the GFZ and RV molecular effects, we carried out further kinetic experiments estimating the combined effects of OV plus GFZ and OV plus RV. The results shown in Table 1 indicate that the presence of OV partially antagonized the stimulation of anion flux induced by the two drugs, both in human and pig RBCs. Figure 6 outlines the RV effect on the Hb oxygen affinity; in particular RV shifts the half-maximal oxygen pressure $\left(\mathrm{P}_{50}\right)$ of both human and pig $\mathrm{Hb}$ towards the left indicating a preferential binding to the R state of Hbs. $\mathrm{Hb}$ interacts with cdb3 modulating the anion flux in both species: this, in the presence of RV, is increased almost by a factor of 3 in human RBCs while is greatly reduced in pig ones.

\section{Discussion}

We showed here that pig erythrocytes are characterized by a higher anion flux compared to human RBCs (Figure 1). Once again, it should outline the presence of the modulation of anion transport due to the interaction of $\mathrm{Hb}$ with cdb3. We have already discussed the involvement of the conformational transition (T-R) of $\mathrm{Hb}$ on the different activities of human B3 in HOS and LOS state. We associated this finding with the structural hindrance caused by the gradual increase of $\mathrm{Hb}$ bound to $\mathrm{cdb} 3$ that would take place on passing from HOS to LOS [17] [26]. In the case of pig RBCs (Figure 2), the stronger involvement of $\mathrm{Hb}$ in the modulation of B3 could be affected by the contribution of free $\mathrm{Cl}^{-}$which is lower in the LOS state as consequence of the binding to $\mathrm{Hb}$. 


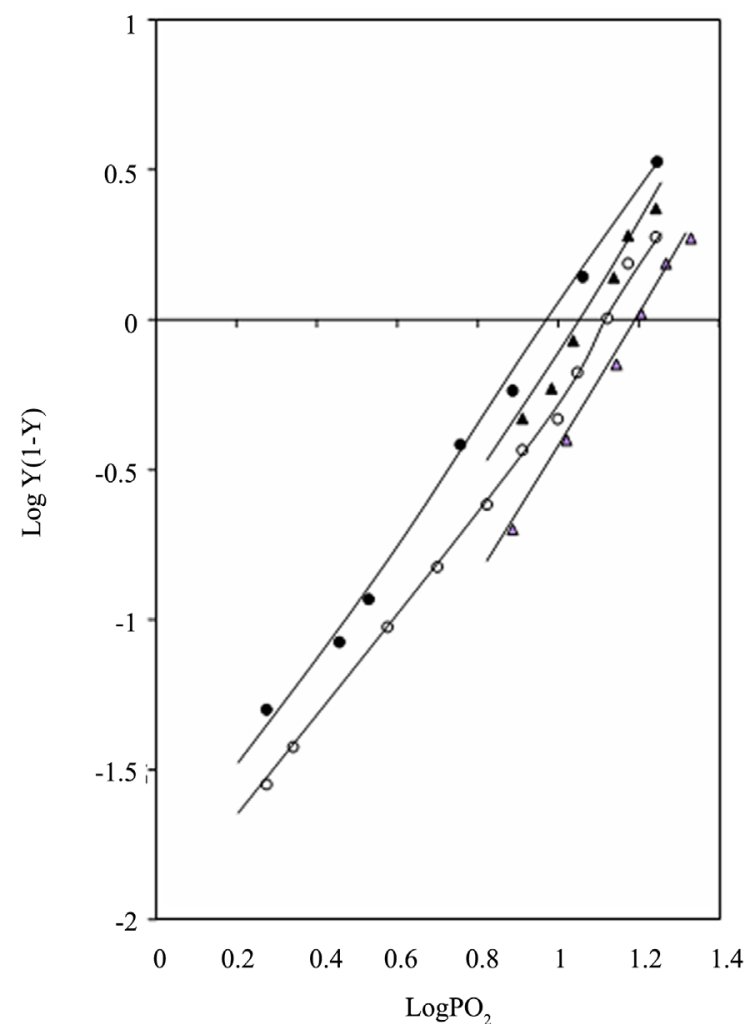

Figure 6. Hill plot for the binding of oxygen to human (circles) and pig (triangles) $\mathrm{Hb}$ in the absence (open symbols) and in the presence (closed symbols) of $0.1 \mathrm{mM} \mathrm{RV}$. Conditions: $0.1 \mathrm{M}$ HEPES buffer plus $0.1 \mathrm{M} \mathrm{NaCl}$ and $3 \mathrm{mM}$ 2,3-DPG at $\mathrm{pH} 7.4,37^{\circ} \mathrm{C}$.

In this context it is important to recall that the $\mathrm{Hb}$ of pig has an important substitution in $\beta 76$ where the Ala present in adult human $\mathrm{Hb}$ is replaced by a Lys [2]. This replacement is responsible for an additional binding site for chloride ion which significantly contributes to lower the overall heat of oxygenation, thus providing a molecular basis for the low effect of temperature on the oxygenation-deoxygenation cycle [33] [34]. We hypothesize that the presence of this additional cluster for chloride in pig $\mathrm{Hb}$ might contribute to the increase of anion flux through B3. In particular, since $\mathrm{HCO}_{3}^{-}$influx across $\mathrm{B} 3$ is coupled with $\mathrm{Cl}^{-}$efflux, it might be argued that the observed difference in B3 activity of pig between LOS and HOS states is induced by the variation of intracellular activity of free $\mathrm{Cl}^{-}$. All these considerations could be closely associated with the low sodium transport (and number of sodium pumps) which has been observed in pig in comparison to human RBCs [35]. Nevertheless the increase of $\mathrm{Cl}^{-}$activity is not sufficient to justify the high anion exchange observed in HOS erythrocyte [17]. Another important event that occurs during the transition HOS-LOS of the RBC is the change of the intracellular concentration of free 2,3-DPG. In this respect, it may be worthwhile to outline that the intraerythrocytic concentration of this organic phosphate in pig can be up to about $10 \mathrm{mM}$ and that 2,3-DPG interacts with the erythrocyte membrane and with B3 in particular [1] [2] [18] [36]. Furthermore, 2,3-DPG causes an increase in the lateral mobility of integral membrane proteins [37] and, at concentrations which are normally present in erythrocytes, can weaken associations in the shell [38]. It cannot be excluded that it may play a role in the regulation of the membrane protein phosphorylation [20]. In other words it is possible to think that in pig RBC, the additional binding sites for chloride present on $\mathrm{Hb}$ and the higher intraerythrocytic concentration of 2,3-DPG may contribute to changing the overall interactions Hb-cdb3 and GE-cdb3 both associated with modulation of the B3 anion flux. Further contribution to this hypothesis comes from comparison of the anion kinetics in the RBC and ghosts of human and pig (Figure 3). Thus, binding competition assays demonstrate that human cdb3 competes with 2,3-DPG for occupancy of the central cleft in the deoxy-Hb tetramer [39] [40] and may bind GE with the same structural region [41]. Therefore, it’s likely that in pig the "excess" of intraerythocytic organic 
phosphate concentration may play a role in weakening the interactions and formation of the membrane complexes (i.e. Hb-cdb3 and GE-cdb3), thereby reducing the effect of these molecules on the modulation of the anion flux.

Furthermore, the effect of OV on B3 flux (Figure 4) induced by the loss of PTP-1B phosphatase activity, may lead to destabilization of B3 phosphorylation-dephosphorylation balance followed by activation of caspase 3 and cleavage of cdb3 with a consequent derangement of anion flux modulation. In the case of pig the lower effect of OV on B3 activity (30\% and 20\% respectively in human and pig RBC) could be due to the high concentration of 2,3-DPG which inhibiting the B3 phosphorylation [40] may counter balance the loss of PTP-1B phosphatase activity.

Similarly, but somewhat more complex is what happens in pig RBC in the presence of RV. RV exerts its effect by interacting preferentially with oxy- $\mathrm{Hb}$; the interaction involves three hydroxyls of stilbene and Pro95, Thr134 and Asp126 of alpha chains [42]. All these residues are conserved in pig Hb so that the polyphenol effect on $\mathrm{Hb}$ oxygen affinity is similar to that observed on human $\mathrm{Hb}$ (Figure 6) [43]. RV binds preferentially to oxyhemoglobin and causes a significant shift of the oxygen dissociation curve (ODC) towards higher oxygen affinity indicating a stabilization of the $\mathrm{R}$ state of the $\mathrm{Hb}$ molecule (on the basis of the simple two-states allosteric model). However, RV causes also an upregulation of B3 tyrosine phosphorylation through the activation of lyn, a kinase of the src family [44]; this Tyr phosphorylation could well be the onset of oxidative stress [45] which might be followed by caspase 3 activation [46] [47] starting a "vicious cycle" that would deprive B3 of its important modulatory site (cdb3) [27] [48]. In pig, the impact on the B3 activity due to phosphorylation may be reduced by the contrasting effect of 2,3-DPG, which causes the release of kinase from the erythrocyte membrane [20] inhibiting the phosphorylation of B3. This is also reflected by the effect of RV on the ghosts of pig, because these structures losing the 2,3-DPG miss its counteraction on the phosphorylation. On the contrary, the effect of GFZ on the B3 activity (Figure 4) more similar in pig than in human RBC and linked to the Hb-GFZ-cdb3 macrocomplex [25] [26] suggests that the interaction between GFZ and $\mathrm{Hb}$ is maintained despite the high concentration of 2,3-DPG which characterizes pig RBCs. Interestingly, the combination of GFZ plus OV does not show a cumulative increase of B3 influx as it is highlighted in the Table 1. These findings and the lack of 2,3-DPG influence on GFZ action in pig RBC support the hypothesis that the fibrate acts on B3 influx through a different pathway with respect to OV and it does not alter the phosphorylation-dephosphorylation balance of RBCs [26]. In contrast with human RBCs, erythrocytes from pig lack glucose-transport activity [49] [50] and rely on plasma inosine as the major physiological energy source [49] [51]. Inosine is transported inside the cells and cleaved to hypoxanthine and ribose 1 phosphate. The ribose moiety can be further catabolized [52]. Pig RBCs utilize inosine as the NADH generator which is essential for enzymatic reduction of met-Hb [53]. This unusual oxidation of NAD allows the glycolysis pathway to continue. An interesting factor in pig RBCs is the production of energy through inosine which, bypassing some points of glycolytic regulation such as the phosphophofructokinase (PFK) and aldolase (ALD), results to be in some way "uncontrolled". Hence, the control of G6P metabolism is exercised only by Glyceraldehyde-3-phosphate dehydrogenase (G3PD) through its binding to B3. These characteristics allow the cell to compensate the lack of availability of glucose that can be utilized through the Rapoport-Luebering cycle or/and the PPP. A further and indirect antioxidant action is performed in HOS pig RBC by the increase of anion exchange through the rapid removal of $\mathrm{CO}_{2}$ and peroxinitrite from cytosol which prevents

Table 1. Effect of OV, GFZ and RV on the rates of sulphate transport in human and pig RBCs (values are the means \pm range of at least five experiments; $P<0.05$ was considered significant).

\begin{tabular}{ccc}
\hline Conditions & $\begin{array}{c}\text { Rate constant }\left(\mathrm{min}^{-1}\right) \\
\text { human RBCs }\end{array}$ & $\begin{array}{c}\text { Rate constant }\left(\mathrm{min}^{-1}\right) \\
\text { pig RBCs }\end{array}$ \\
\hline Control & $0.012 \pm 0.003$ & $0.025 \pm 0.004$ \\
$3 \mathrm{mM} \mathrm{OV}$ & $0.018 \pm 0.004$ & $0.032 \pm 0.003$ \\
$3 \mathrm{mM} \mathrm{GFZ}$ & $0.052 \pm 0.001$ & $0.142 \pm 0.005$ \\
$3 \mathrm{mM}$ OV plus 3 mM GFZ & $0.032 \pm 0.005$ & $0.039 \pm 0.004$ \\
0.1 mM RV & $0.033 \pm 0.008$ & $0.033 \pm 0.005$ \\
$3 \mathrm{mM}$ OV plus 0.1 mM RV & & $0.026 \pm 0.003$
\end{tabular}


the subsequent formation of secondary radicals such as carbonate and nitrogen dioxide or hydroxyl radicals. Alternatively, peroxynitrite or peroxynitrous acid may also undergo homolytic fission to generate one-electron oxidants, hydroxyl and nitrogen dioxide radicals [54] [55].

The results of our study give new insights on significant issues that should not be disregarded in future studies on mammalian erythrocytes.

\section{References}

[1] Willford, D.C. and Hill, E.P. (1986) Modest Effect of Temperature on the Porcine Oxygen Dissociation Curve. Respiration Physiology, 64, 113-123. http://dx.doi.org/10.1016/0034-5687(86)90035-6

[2] Condò, S.G., Corda, M., Sanna, M.T., Pellegrini, M.G., Ruiz, M.P., Castagnola, M. and Giardina, B. (1992) Molecular Basis of Low-Temperature Sensitivity in Pig Hemoglobins. European Journal of Biochemistry, 209, 773-776. http://dx.doi.org/10.1111/j.1432-1033.1992.tb17347.x

[3] Dixon, E. and Wilson, B.A. (1981) Erythrocyte Metabolism: Kinetic and Electrophoretic Analyses of Pig Red Cell Hexokinase. Journal of Experimental Zoology, 215, 63-76. http://dx.doi.org/10.1002/jez.1402150108

[4] Stocchi, V., Magnani, M., Novelli, G., Dachà, M. and Fornaini, G. (1983) Pig Red Blood Cell Hexokinase: Evidence for the Presence of Hexokinase Types II and III, and Their Purification and Characterization. Archives of Biochemistry and Biophysics, 226, 365-376. http://dx.doi.org/10.1016/0003-9861(83)90303-X

[5] Magnani, M., Stocchi, V., Serafini, N., Piatti, E., Dachà, M. and Fornaini, G. (1983) Pig Red Blood Cell Hexokinase: Regulatory Characteristics and Possible Physiological Role. Archives of Biochemistry and Biophysics, 226, 377-387. http://dx.doi.org/10.1016/0003-9861(83)90304-1

[6] Watts, R.P., Brendel, K., Luthra, M.G. and Kim, H.D. (1979) Inosine from Liver as a Possible Energy Source for Pig Red Blood Cells. Life Sciences, 25, 1577-1582. http://dx.doi.org/10.1016/0024-3205(79)90440-5

[7] Jones, G.L. and Masters, C.J. (1976) On the Comparative Characteristics of Mammalian Catalases. Comparative Biochemistry and Physiology Part B, 55, 511-518. http://dx.doi.org/10.1016/0305-0491(76)90009-2

[8] Maral, J., Puget, K. and Michelson, A.M. (1977) Comparative Study of Superoxide Dismutase, Catalase and Glutathione Peroxidase Levels in Erythrocytes of Different Animals. Biochemical and Biophysical Research Communications, 77, 1525-1535. http://dx.doi.org/10.1016/S0006-291X(77)80151-4

[9] Zhang, D., Kiyatkin, A., Bolin, J.T. and Low, P.S. (2000) Crystallographic Structure and Functional Interpretation of the Cytoplasmic Domain of Erythrocyte Membrane Band 3. Blood, 96, 2925-2933.

[10] Giardina, B., Messana, I., Scatena, R. and Castagnola, M. (1995) The Multiple Functions of Haemoglobin. Critical Reviews in Biochemistry and Molecular Biology, 30, 165-196. http://dx.doi.org/10.3109/10409239509085142

[11] Lewis, I.A., Campanella, M.E., Markley, J.L. and Low, P.S. (2009) Role of Band 3 in Regulating Metabolic Flux of Red Blood Cells. PNAS, 106, 18515-18520. http://dx.doi.org/10.1073/pnas.0905999106

[12] Russo, A., Tellone, E., Ficarra, S., Giardina, B., Bellocco, E., Laganà, G., Leuzzi, U., Kotyk, A. and Galtieri, A. (2008) Band 3 Protein Function in Teleost Fish Erythrocytes: Effect of Oxygenation-Deoxygenation. Physiological Research, 57, 49-54.

[13] Zijlstra, W.G., Buursma, A. and Meeuwsen-Van Der Roest, W.P. (1991) Absorption Spectra of Human Fetal and Adult Oxyhemoglobin, Deoxyhemoglobin, Carboxyhemoglobin and Methemoglobin. Clinical Chemistry, 37, 1633-1638.

[14] Labotka, R.J. (1984) Measurement of Intracellular pH and Deoxyhemoglobin Concentration in Deoxygenated Erythrocytes by Phosphorus-31 Nuclear Magnetic Resonance. Biochemistry, 23, 5549-5555. http://dx.doi.org/10.1021/bi00318a026

[15] Giardina, B. and Amiconi, G. (1981) Measurement of Binding of Gaseous and Nongaseous Ligands to Hemoglobin by Conventional Spectrophotometric Procedures. Methods in Enzymology, 76, 417-427. http://dx.doi.org/10.1016/0076-6879(81)76133-0

[16] Romano, L., Peritore, D., Simone, E., Sidoti, A., Trischitta, F. and Romano, P. (1998) Chloride-Sulfate Exchange Chemically Measured in Human Erythrocyte Ghosts. Cellular and Molecular Biology, 44, 351-355.

[17] Galtieri, A., Tellone, E., Romano, L., Misiti, F., Bellocco, E., Ficarra, S., Russo, A., Di Rosa, D., Castagnola, M., Giardina, B. and Messana, I. (2002) Band-3 Protein Function in Human Erythrocytes: Effect of Oxygenation-Deoxygenation. Biochimica et Biophysica Acta, 1564, 214-218. http://dx.doi.org/10.1016/S0005-2736(02)00454-6

[18] Moriyama, R., Nagatomi, Y., Hoshino, F. and Makino, S. (1994) Amino Acid Sequences around Exofacial Proteolytic Cleavage Sites of Band 3 from Bovine and Porcine Erythrocytes. International Journal of Biochemistry, 26, 133-137. http://dx.doi.org/10.1016/0020-711X(94)90206-2

[19] Moriyama, R., Lombardo, C.R., Workman, R.F. and Low, P.S. (1993) Regulation of Linkages between the Erythrocyte Membrane and Its Skeleton by 2,3-Diphosphoglycerate. The Journal of Biological Chemistry, 268, 10990-10996. 
[20] Conway, R.G. and Tao, M. (1981) Effect of 2,3-Diphosphoglyceric Acid on the Human Erythrocyte Membrane Phosphorylation System. The Journal of Biological Chemistry, 256, 11932-11938.

[21] Chao, T.S. and Tao, M. (1991) Effect of 2,3-Diphosphoglycerate on the Phosphorylation of Protein 4.1 by Protein Kinase C. Archives of Biochemistry and Biophysics, 285, 221-226. http://dx.doi.org/10.1016/0003-9861(91)90352-J

[22] Cuncic, C., Detich, N., Ethier, D., Tracey, A.S., Gresser, M.J. and Ramachandran, C. (1999) Vanadate Inhibition of Protein Tyrosine Phosphatases in Jurkat Cells: Modulation by Redox State. Journal of Biological Inorganic Chemistry, 4, 354-359. http://dx.doi.org/10.1007/s007750050322

[23] Bordin, L., Clari, G., Moro, I., Dalla Vecchia, F. and Moret, V. (1995) Functional Link between Phosphorylation State of Membrane Proteins and Morphological Changes of Human Erythrocytes. Biochemical and Biophysical Research Communications, 213, 249-257. http://dx.doi.org/10.1006/bbrc.1995.2123

[24] Brunati, A.M., Bordin, L., Clari, G., James, P., Quadroni, M., Baritono, E., Pinna, L.A. and Donella-Deana, A. (2000) Sequential Phosphorylation of Protein Band 3 by Syk and Lyn Tyrosin Kinases in Intact Human Erythrocytes. Identification of Primary and Secondary Phosphorylation Sites. Blood, 96,1550-1557.

[25] Tellone, E., Ficarra, S., Scatena, R., Giardina, B., Kotyk, A., Russo, A., Colucci, D., Bellocco, E., Laganà, G. and Galtieri, A. (2008) Influence of Gemfibrozil on Sulphate Transport in Human Erythrocytes during the OxygenationDeoxygenation Cycle. Physiological Research, 57, 621-629.

[26] Tellone, E., Ficarra, S., Giardina, B., Scatena, R., Russo, A., Clementi, M.E., Misiti, F., Bellocco, E. and Galtieri, A. (2008) Oxidative Effects of Gemfibrozil on Anion Influx and Metabolism in Normal and Beta-Thalassemic Erythrocytes: Physiological Implications. Journal of Membrane Biology, 224, 1-8. http://dx.doi.org/10.1007/s00232-008-9122-8

[27] Galtieri, A., Tellone, E., Ficarra, S., Russo, A., Bellocco, E., Barreca, D., Scatena, R., Laganà, G., Lezzi, U. and Giardina, B. (2010) Resveratrol Treatment Induces Redox Stress in Red Blood Cells: A Possible Role of Caspase 3 in Metabolism and Anion Transport. Biological Chemistry, 391, 1057-1065. http://dx.doi.org/10.1515/bc.2010.100

[28] Frick, M.H., Elo, O., Haapa, K., Heinonen, O.P., Heinsalmi, P., Helo, P., Huttunen, J.K., Kaitaniemi, P., Oskinen, P. and Manninen, V. (1987) Helsinki Heart Study: Primary-Prevention Trial with Gemfibrozil in Middle-Aged Men with Dyslipidemia. Safety of Treatment, Changes in Risk Factors, and Incidence of Coronary Heart Disease. New England Journal of Medicine, 317, 1237-1245. http://dx.doi.org/10.1056/NEJM198711123172001

[29] Manninen, V., Elo, M.O., Frick, M.H., Haapa, K., Heinonen, O.P., Heinsalmi, P., Helo, P., Huttunen, J.K., Kaitaniemi, P., Koskinen, P., et al. (1988) Lipid Alterations and Decline in the Incidence of Coronary Heart Disease in the Helsinki Heart Study. JAMA, 260, 641-651. http://dx.doi.org/10.1001/jama.1988.03410050061031

[30] Elmali, N., Esenkaya, I., Harma, A., Ertem, K., Turzok, Y. and Mizrak, B. (2005) Effect of Resveratrol in Experimental Osteoarthritis in Rabbits. Inflammation Research, 54, 158-162. http://dx.doi.org/10.1007/s00011-004-1341-6

[31] Elmali, N., Baysal, O., Harma, A., Esenkaya, I. and Mizrak, B. (2007) Effects of Resveratrol in Inflammatory Arthritis. Inflammation, 30, 1-6. http://dx.doi.org/10.1007/s10753-006-9012-0

[32] Shakibaei, M., John, T., Schulze-Tanzil, G., Lehmann, I. and Mobasheri, A. (2007) Suppression of NF- $\kappa$ B Activation by Curcumin Leads to Inhibition of Expression of Cyclo-Oxygenase-2 and Matrix Metalloproteinase-9 in Human Articular Chondrocytes: Implications for the Treatment of Osteoarthritis. Biochemical Pharmacology, 73, 1434-1445. http://dx.doi.org/10.1016/j.bcp.2007.01.005

[33] Fronticelli, C., Sanna, M.T., Perez-Alvarado, G.C., Karavitis, M., Lu, A.L. and Brinigar, W.S. (1995) Allosteric Modulation by Tertiary Structure in Mammalian Hemoglobins. Journal of Biological Chemistry, 270, 30588-30592. http://dx.doi.org/10.1074/jbc.270.51.30588

[34] De Rosa, M.C., Castagnola, M., Bertonati, C., Galtieri, A. and Giardina, B. (2004) From the Arctic to Fetal Life: Physiological Importance and Structural Basis of an "Additional" Chloride-Binding Site in Haemoglobin. Biochemical Journal, 380, 889-896. http://dx.doi.org/10.1042/bj20031421

[35] Whittaker, J., Hawkins, M. and Swaminathan, R. (1983) Characteristics of Sodium Transport in Pig (Sus scrofa) Erythrocytes. Biochemical Medicine, 30, 43-48. http://dx.doi.org/10.1016/0006-2944(83)90006-6

[36] Thevenin, B.J., Periasamy, N., Shohet, S.B. and Verkman, A.S. (1994) Segmental Dynamics of the Cytoplasmic Domain of Erythrocyte Band 3 Determined by Time-Resolved Fluorescence Anisotropy: Sensitivity to $\mathrm{pH}$ and Ligand Binding. Proceedings of the National Academy of Sciences of the United States of America, 91, 1741-1745. http://dx.doi.org/10.1073/pnas.91.5.1741

[37] Schindler, M., Koppel, D.E. and Sheetz, M.P. (1980) Modulation of Membrane Protein Lateral Mobility by Polyphosphates and Polyamines. Proceedings of the National Academy of Sciences of the United States of America, 77, 14571461. http://dx.doi.org/10.1073/pnas.77.3.1457

[38] Sheetz, M.P. and Casaly, J. (1980) 2,3-Diphosphoglycerate and ATP Dissociate Erythrocyte Membrane Skeletons. The Journal of Biological Chemistry, 255, 9955-9960. 
[39] Chètrite, G. and Cassoly, R. (1985) Affinity of Hemoglobin for the Cytoplasmic Fragment of Human Erythrocyte Membrane Band 3. Equilibrium Measurements at Physiological pH Using Matrix-Bound Proteins: The Effects of Ionic Strength, Deoxygenation and of 2,3-Diphosphoglycerate. Journal of Molecular Biology, 185, 639-644. http://dx.doi.org/10.1016/0022-2836(85)90076-2

[40] Walder, J.A., Chatterjee, R., Steck, T.L., Low, P.S., Musso, G.F., Kaiser, E.T., Rogers, P.H. and Arnone, A. (1984) The Interaction of Hemoglobin with the Cytoplasmic Domain of Band 3 of the Human Erythrocyte Membrane. The Journal of Biological Chemistry, 259, 10238-10246.

[41] Weber, R.E., Voelter, W., Fago, A., Echner, H., Campanella, E. and Low, P.S. (2004) Modulation of Red Cell Glycolysis: Interactions between Vertebrate Hemoglobins and Cytoplasmic Domains of Band 3 Red Cell Membrane Proteins. AJP: Regulatory, Integrative and Comparative Physiology, 287, R454-R464. http://dx.doi.org/10.1152/ajpregu.00060.2004

[42] Perutz, M.F., Fermi, G., Abraham, D.J., Poyart, C. and Bursaux, E. (1986) Hemoglobin as a Receptor of Drugs and Peptides: X-Ray Studies of the Stereochemistry of Binding. Journal of the American Chemical Society, 108, 10641078. http://dx.doi.org/10.1021/ja00265a036

[43] Kleinschmidt, T. and Sgouros, J.G. (1987) Hemoglobin Sequences. Biological Chemistry Hoppe-Seyler, 368, 579-615.

[44] Maccaglia, A., Mallozzi, C. and Minetti, M. (2003) Differential Effects of Quercetin and Resveratrol on Band 3 Tyrosine Phosphorylation Signalling of Red Blood Cells. Biochemical and Biophysical Research Communications, 305, 541-547. http://dx.doi.org/10.1016/S0006-291X(03)00762-9

[45] Zipser, Y. and Kosover, N.S. (1996) Phosphotyrosine Phosphatase Associated with Band 3 Protein in Human Erythrocyte Membrane. Biochemical Journal, 314, 881-887. http://dx.doi.org/10.1042/bj3140881

[46] Mandal, D., Moitra, P.K., Saha, S. and Basu, J. (2002) Caspase 3 Regulates Phosphatidylserine Externalization and Phagocitosis of Oxidatively Stressed Erythrocytes. FEBS Letters, 513, 184-188. http://dx.doi.org/10.1016/S0014-5793(02)02294-9

[47] Mandal, D., Baudin-Creuza, V., Bhattacharyy, A., Pathak, S., Delaunay, J., Kundu, M. and Basu, J. (2003) Caspase 3-Mediated Proteolysis of the N-Terminal Cytoplasmic Domain of the Human Erythroid Anion Exchanger 1 (Band 3). Journal of Biological Chemistry, 278, 52551-52558. http://dx.doi.org/10.1074/jbc.M306914200

[48] Ficarra, S., Tellone, E., Giardina, B., Scatena, R., Russo, A., Misiti, F., Clementi, M.E., Colucci, D., Bellocco, E., Laganà, G., Barreca, D. and Galtieri, A. (2009) Derangement of Erythrocytic AE1 in Beta-Thalassemia by Caspase 3: Pathogenic Mechanisms and Implications in Red Blood Cell Senescence. Journal of Membrane Biology, 228, 43-49. http://dx.doi.org/10.1007/s00232-009-9157-5

[49] Kim, H.D. and McManus, T.J. (1971) Studies on the Energy Metabolism of Pig Red Cells. I. The Limiting Role of Membrane Permeability in Glycolysis. Biochimica et Biophysica Acta, 230, 1-11. http://dx.doi.org/10.1016/0304-4165(71)90048-1

[50] Young, J.D., Paterson, A.R.P. and Henderson, J.F. (1985) Nucleoside Transport and Metabolism in Erythrocytes from the Yucatan Miniature Pig. Evidence That Inosine Function as an in Vivo Substrate. Biochimica et Biophysica Acta, 842, 214-224. http://dx.doi.org/10.1016/0304-4165(85)90205-3

[51] Young, J.D., Jarvis, S.M., Clanachan, A.S., Henderson, J.F. and Paterson, A.R. (1986) Nitrobenzylthioinosine: An in Vivo Inhibitor of Pig Erythrocytes Energy Metabolism. American Journal of Physiology, 251, 90-94.

[52] Jurkowitz, M.S., Litsky, M.L., Browning, M.J. and Hohl, C.M. (1998) Adenosine, Inosine, and Guanosine Protect Glial Cells during Glucose Deprivation and Mitochondrial Inhibition: Correlation between Protection and ATP Preservation. Journal of Neurochemistry, 71, 535-548. http://dx.doi.org/10.1046/j.1471-4159.1998.71020535.x

[53] Sartorelli, P., Paltrinieri, S., Agnes, F. and Baglioni, T. (1996) Role of Inosine in Prevention of Methaemoglobinaemia in the Pig: In Vitro Studies. Journal of Veterinary Medicine Series A, 43, 489-493. http://dx.doi.org/10.1111/j.1439-0442.1996.tb00479.x

[54] Romero, N., Denicola, A., Souza, J.M. and Radi, R. (1999) Diffusion of Peroxynitrite in the Presence of Carbon Dioxide. Archives of Biochemistry and Biophysics, 368, 23-30. http://dx.doi.org/10.1006/abbi.1999.1272

[55] Szabò, C., Ischiropoulos, H. and Radi, R. (2007) Peroxynitrite: Biochemistry, Pathophysiology and Development of Therapeutics. Nature Reviews Drug Discovery, 6, 662-680. http://dx.doi.org/10.1038/nrd2222 